\title{
Alogliptin after acute coronary syndrome in patients with type 2 diabetes: a renal function stratified analysis of the EXAMINE trial
}

João Pedro Ferreira ${ }^{1,2^{*}}$, Cyrus Mehta ${ }^{3,4}$, Abhinav Sharma ${ }^{5}$, Steven E. Nissen ${ }^{6}$, Patrick Rossignol ${ }^{1,2}$ and Faiez Zannad ${ }^{1,2}$

\begin{abstract}
Background: The EXAMINE trial tested the efficacy and safety of alogliptin, an inhibitor of dipeptidyl peptidase 4, compared with placebo in 5380 patients with type 2 diabetes and a recent acute coronary syndrome. Because alogliptin is cleared by the kidney, patients were stratified according to screening renal function within two independently randomized strata: (1) estimated glomerular filtration rate (eGFR) $\geq 60 \mathrm{ml} / \mathrm{min} / 1.73 \mathrm{~m}^{2}$ and (2) $\mathrm{eGFR}<60 \mathrm{ml} / \mathrm{min} / 1.73 \mathrm{~m}^{2}$. We aim to assess the efficacy and safety of alogliptin vs. placebo according to the renal function strata.

Methods: Cox-proportional hazard models with an interaction term by renal function strata were used. The primary endpoint was a composite of cardiovascular death, nonfatal myocardial infarction (MI), or nonfatal stroke.

Results: Patient characteristics were balanced within each renal function strata. In total, 3946 patients were randomized within the eGFR $\geq 60$ stratum, and 1434 patients within the eGFR $<60$ stratum. The effect of alogliptin was modified by the renal function strata. Primary outcome: eGFR $\geq 60 \mathrm{HR}=0.81,95 \% \mathrm{Cl}, 0.65-0.99$, and eGFR $<60 \mathrm{HR}=1.20,95 \% \mathrm{Cl}$, 0.95-1.53; interaction $_{p}=0.014$. Cardiovascular death: eGFR $\geq 60 \mathrm{HR}=0.61,95 \% \mathrm{Cl}, 0.42-0.88$, and eGFR $<60 \mathrm{HR}=1.16,95 \% \mathrm{Cl}, 0.82-1.65$; interaction $_{\mathrm{p}}=0.013$. Non-fatal Ml: eGFR $\geq 60 \mathrm{HR}=0.86,95 \% \mathrm{Cl}, 0.66-1.13$, and eGFR $<60 \mathrm{HR}=1.48,95 \% \mathrm{Cl}, 1.07-2.06$; interaction $_{\mathrm{p}}=0.013$.

Conclusions: Alogliptin may benefit patients with eGFR $\geq 60$, but may be detrimental to patients with eGFR $<60 \mathrm{ml} / \mathrm{min} /$ $1.73 \mathrm{~m}^{2}$. These hypothesis-generating findings require further validation to assess the potential benefit and risk of alogliptin across the renal function spectrum among patients with type 2 diabetes and a recent acute coronary syndrome.
\end{abstract}

Trial registration: ClinicalTrials.gov, NCT00968708

Keywords: Alogliptin, Renal function, Stratification, Outcomes

\footnotetext{
*Correspondence: j.ferreira@chru-nancy.fr; jp7ferreira@hotmail.com

'Université de Lorraine, Centre d'Investigations Cliniques Plurithématique Inserm 1433, Nancy, France, CHRU de Nancy, Inserm U1116, Nancy, France, FCRIN INI-CRCT, Nancy, France

${ }^{2}$ INSERM U1116, CHRU, F-CRIN INI-CRCT (Cardiovascular and Renal Clinical Trialists), 4 rue du Morvan, 54500 Vandoeuvre les Nancy, Nancy, France

Full list of author information is available at the end of the article
}

(c) The Author(s). 2020 Open Access This article is licensed under a Creative Commons Attribution 4.0 International License, which permits use, sharing, adaptation, distribution and reproduction in any medium or format, as long as you give appropriate credit to the original author(s) and the source, provide a link to the Creative Commons licence, and indicate if changes were made. The images or other third party material in this article are included in the article's Creative Commons licence, unless indicated otherwise in a credit line to the material. If material is not included in the article's Creative Commons licence and your intended use is not permitted by statutory regulation or exceeds the permitted use, you will need to obtain permission directly from the copyright holder. To view a copy of this licence, visit http://creativecommons.org/licenses/by/4.0/ The Creative Commons Public Domain Dedication waiver (http://creativecommons.org/publicdomain/zero/1.0/) applies to the data made available in this article, unless otherwise stated in a credit line to the data. 


\section{Background}

Type 2 diabetes epidemic is a global public health issue and is strongly associated with atherosclerotic cardiovascular disease [1]. To date, few drugs have demonstrated their efficacy and safety according to baseline renal function, which may impact treatment decisions in a personalized manner [2]. Concerns regarding adverse cardiovascular outcomes with antidiabetic agents [3, 4] prompted the Food and Drug Administration (FDA) to issue guidance (in December 2008) that included specific requirements for cardiovascular safety assessment before and after the approval of new antidiabetic therapies [5]. Regulatory agencies in other countries have adopted similar policies.

Alogliptin is a selective inhibitor of dipeptidyl peptidase 4 (DPP-4) approved for the treatment of type 2 diabetes [6]. The Examination of Cardiovascular Outcomes with Alogliptin versus Standard of Care (EXAMINE) trial sought to determine whether alogliptin was noninferior to placebo with respect to major cardiovascular events in patients with type 2 diabetes with recent acute coronary syndrome (a very high cardiovascular risk population) [7]. In the overall population, alogliptin significantly reduced glycated hemoglobin without increasing the rates of major adverse cardiovascular events [7, 8].

Because renal function is strongly associated with outcomes in diabetic populations and alogliptin is predominantly cleared by the kidney [9-11], the EXAMINE trial had a prespecified stratification according to the estimated glomerular filtration rate (eGFR) at screening. The two independently randomized strata were (1) eGFR $\geq 60 \mathrm{ml} / \mathrm{min} / 1.73 \mathrm{~m}^{2}$ and (2) eGFR $<60 \mathrm{ml} / \mathrm{min} / 1.73 \mathrm{~m}^{2}$, reflecting patients with normal/near normal and impaired renal function, respectively [12].

The aim of the present analysis is to assess the effect of alogliptin according to the screening renal function strata.

\section{Methods \\ Study design}

Details of the EXAMINE study design were previously published [7, 12]. In short, the EXAMINE trial was a multicenter, randomized, double-blind trial. The steering committee, consisting of academic members and three nonvoting representatives of the sponsor (Takeda Development Center Americas), designed and oversaw the conduct of the trial. An independent data and safety monitoring committee monitored the trial and had access to the unblinded data. The appropriate national and institutional regulatory authorities and ethics committees approved the study design, and all participants provided written informed consent.

\section{Study patients}

Patients were eligible for enrolment if they had received a diagnosis of type 2 diabetes mellitus, were receiving antidiabetic therapy (other than a DPP-4 inhibitor or GLP-1 analogue), and had had an acute coronary syndrome within 15 to 90 days before randomization. Further criteria for the diagnosis of type 2 diabetes included a glycated hemoglobin level of 6.5 to $11.0 \%$ at screening, or if the antidiabetic regimen included insulin, a glycated hemoglobin level of 7.0 to $11.0 \%$. Acute coronary syndromes included acute myocardial infarction and unstable angina requiring hospitalization. Major exclusion criteria were a diagnosis of type 1 diabetes, unstable cardiac disorders (e.g., New York Heart Association class IV heart failure, refractory angina, uncontrolled arrhythmias, critical valvular heart disease, or severe uncontrolled hypertension), and dialysis within 14 days before screening.

\section{Study treatment}

Patients were randomly assigned to receive alogliptin or placebo, administered in a double-blind fashion, in addition to standard-of-care treatment for type 2 diabetes mellitus. Throughout the study, patients were required to receive standard-of-care treatment for type 2 diabetes and cardiovascular risk factors according to regional guidelines.

\section{Stratification according to renal function}

Stratification according to eGFR (calculated with the use of the Modification of Diet in Renal Disease formula [13]) was performed at screening which that occurred 9 (7-13) days before the randomization. In the screening visit, patients were allocated to one of the following strata: (1) eGFR $\geq 60 \mathrm{ml} / \mathrm{min} / 1.73 \mathrm{~m}^{2} \quad(\mathrm{eGFR} \geq 60)$ and (2) eGFR $<60 \mathrm{ml} / \mathrm{min} / 1.73 \mathrm{~m}^{2}(\mathrm{eGFR}<60)$. As prespecified, patients were randomized within each stratum.

Because alogliptin is cleared by the kidney, the doses of alogliptin (and matching placebo) were modified according to kidney function at the time of randomization and could be adjusted during the postrandomization period. The daily doses of the study drug were as follows: $25 \mathrm{mg}$ in patients with an eGFR $\geq 60 \mathrm{ml} / \mathrm{min} / 1.73 \mathrm{~m}^{2}, 12.5 \mathrm{mg}$ in patients with an eGFR of 30 to $<60 \mathrm{ml} / \mathrm{min} / 1.73 \mathrm{~m}^{2}$, and $6.25 \mathrm{mg}$ in patients with an $\mathrm{eGFR}<30 \mathrm{ml} / \mathrm{min} / 1.73 \mathrm{~m}^{2}$.

\section{Endpoints}

The primary endpoint was a composite of death from cardiovascular causes, nonfatal myocardial infarction (MI), or nonfatal stroke (3-point major adverse cardiovascular events [MACE]). The principal secondary endpoint was the primary composite endpoint with the addition of urgent revascularization due to unstable angina within $24 \mathrm{~h}$ after hospital admission. Exploratory endpoints included death from cardiovascular causes and death from any cause. The endpoint of hospital 
admission for heart failure (HF) was defined as an inpatient admission or an emergency department visit of more than $12 \mathrm{~h}$ with clinical manifestations of HF, including new or worsening dyspnea, orthopnea, paroxysmal nocturnal dyspnea, peripheral edema, bibasilar rales on pulmonary examination, jugular venous distention, new third heart sound, radiographic evidence of HF, and parenteral diuretic, inotropic, or vasodilator therapy, ultrafiltration or dialysis, or mechanical or surgical intervention (including heart transplant). Safety endpoints included angioedema, hypoglycemia, pancreatitis, cancer, and the results of laboratory testing. An independent central adjudication committee adjudicated all suspected primary endpoint events and other cardiovascular endpoints, as well as all deaths.

\section{Statistical analysis}

All analyses were done by the intention to treat principle. Baseline characteristics were summarized as frequencies for categorical variables and mean \pm standard deviation (SD) or median (percentile 25-75) according to the variables' distribution on the histogram. Time to the first occurrence of an endpoint component was analyzed with Cox proportional hazards model within each screening renal function stratum and in the whole population with an interaction term on the eGFR strata for assessing subgroup heterogeneity. Cumulative event rates per 100person years are also reported. For studying the treatment effect on myocardial infarction, a competing risk model was used, using death as competing event as described by Fine and Gray [14]. Changes from baseline to the last visit in glycated hemoglobin (HbA1c), HDL, LDL, total cholesterol, triglycerides, eGFR, and urinary albumin-tocreatinine ration (UACR) were assessed with an ANCOVA model with terms for treatment, renal function at baseline, and the corresponding baseline $\mathrm{HbA1c}$ values as covariates and reported within each eGFR stratum. Repeated measures were available for HBA1c, LDL, HDL, total cholesterol, triglycerides, body mass index, creatinine, eGFR, UACR, systolic and diastolic blood pressure, and $\mathrm{C}$-reactive protein. The between treatment arm differences in the changes of these parameters along time (months) were assessed (within each screening renal function stratum) using repeated measures multilevel mixedeffects linear regression models, with time, treatment, and an interaction of treatment by time as fixed effects and random-effects at the patient level. All statistical analyses were assessed at a two-sided significance level of 5\%, and all confidence intervals (CIs) were reported as two-sided values with a confidence level of $95 \%$. No adjustments were made to the nominal $p$ values for multiple testing. All statistical analyses were performed with Stata (StataCorp ${ }^{\circ}$, version 16.1). This study is registered with ClinicalTrials.gov, number NCT00968708.

\section{Results}

\section{Study patients by renal function strata}

A total of 5380 patients were recruited: 3946 within the eGFR $\geq 60$ stratum and 1434 within the eGFR $<60$ stratum. As per-strata procedure, the groups were well balanced with regard to their characteristics and nonstudy medications within each stratum (Table 1). The comparison of patients' characteristics between the eGFR strata are presented in Additional file: Table S1. Compared with patients in the eGFR $\geq 60$ stratum, those in the eGFR $<60$ stratum were older, had longer duration of diabetes, and had more comorbid conditions. The median duration of follow-up was 533 days (pct $_{25-75}$ 280-751).

Changes in HbA1c levels over time are shown in Fig. 1. The mean HbA1c change from baseline was similar in both renal function strata: $-0.27 \%$ in the alogliptin group vs. $+0.05 \%$ in the placebo group within the eGFR $\geq 60$ stratum and $-0.30 \%$ in the alogliptin group vs. $+0.05 \%$ in the placebo group within the eGFR $<60$ stratum; $p$ for between eGFR strata interaction $=0.61$. The between treatment arm HbA1c differences were significant at each studied time point ( $p<0.001$ for all time point comparisons). Within strata changes (from baseline to the last visit) in HbA1c, HDL, LDL, total cholesterol, triglycerides, eGFR, and UACR did not present major differences between alogliptin and placebo groups (Additional file: Table S2). Within each eGFR stratum, the between treatment arm differences in the repeated measures of total, LDL, and HDL cholesterol; body mass index; creatinine; eGFR; UACR; systolic and diastolic blood pressure; and C-reactive protein were not significantly different after adjusting for multiple comparisons at each studied time point $(p>0.05$ for all comparisons; Additional file: Figure S1).

\section{Primary and secondary endpoints by renal function strata} Within the eGFR $\geq 60$ stratum, the primary outcome occurred in 192 (9.8\%) patients in the placebo group and $157(7.9 \%)$ patients in the alogliptin group, HR $(95 \% \mathrm{CI})$ $=0.81(0.65-0.99)$, whereas within the eGFR $<60$ stratum, the primary outcome occurred in 124 (17.3\%) patients in the placebo group and $148(20.6 \%)$ patients in the alogliptin group, $\mathrm{HR}(95 \% \mathrm{CI})=1.20(0.95-1.53)$; $p$ for interaction between renal function strata $=0.014$ (Fig. 2). Within the eGFR $\geq 60$ stratum, the principal secondary outcome occurred in $226(11.5 \%)$ patients in the placebo group and 189 (9.5\%) patients in the alogliptin group, $\mathrm{HR}(95 \% \mathrm{CI})=0.82(0.68-0.99)$, whereas within the eGFR $<60$ stratum, the principal secondary outcome occurred in $133(18.6 \%)$ patients in the placebo group and $155(21.6 \%)$ patients in the alogliptin group, $\mathrm{HR}(95 \% \mathrm{CI})=1.17(0.93-1.47) ; p$ for interaction 
Table 1 Baseline characteristics of the study population by screening renal function strata and study drug

\begin{tabular}{|c|c|c|c|c|c|c|}
\hline \multirow{2}{*}{$\begin{array}{l}\text { Renal function strata } \\
\text { Study drug }\end{array}$} & \multicolumn{3}{|c|}{ eGFR $\geq 60$ stratum } & \multicolumn{3}{|c|}{ eGFR $<60$ stratum } \\
\hline & Placebo & Alogliptin & $p$ value & Placebo & Alogliptin & $p$ value \\
\hline$N$ & 1963 & 1983 & & 716 & 718 & \\
\hline Age (years), mean $\pm S D$ & $58.9 \pm 9.3$ & $59.1 \pm 9.5$ & 0.40 & $65.8 \pm 9.7$ & $66.2 \pm 9.4$ & 0.43 \\
\hline Age $<65$ years & $1424(72.5 \%)$ & $1419(71.6 \%)$ & 0.49 & $321(44.8 \%)$ & 309 (43.0\%) & 0.49 \\
\hline Age $\geq 65$ years & $539(27.5 \%)$ & $564(28.4 \%)$ & & $395(55.2 \%)$ & $409(57.0 \%)$ & \\
\hline Male sex & $1427(72.7 \%)$ & $1413(71.3 \%)$ & 0.31 & $396(55.3 \%)$ & $415(57.8 \%)$ & 0.34 \\
\hline Diabetes duration (years), median (IQR) & $6.4(2.5,12.0)$ & $6.2(2.2,11.7)$ & 0.22 & $10.0(4.3,16.8)$ & $10.4(4.4,17.3)$ & 0.50 \\
\hline $\mathrm{BMI}\left(\mathrm{kg} / \mathrm{m}^{2}\right)$, mean $\pm \mathrm{SD}$ & $29.6 \pm 5.7$ & $29.5 \pm 5.3$ & 0.59 & $29.3 \pm 5.9$ & $29.2 \pm 5.7$ & 0.56 \\
\hline Race & & & 0.55 & & & 0.98 \\
\hline White & $1460(74.4 \%)$ & $1475(74.4 \%)$ & & $483(67.5 \%)$ & $491(68.4 \%)$ & \\
\hline Asian & $360(18.3 \%)$ & $369(18.6 \%)$ & & $182(25.4 \%)$ & $178(24.8 \%)$ & \\
\hline Black & $88(4.5 \%)$ & $74(3.7 \%)$ & & $27(3.8 \%)$ & $27(3.8 \%)$ & \\
\hline Other & $55(2.8 \%)$ & $65(3.3 \%)$ & & $24(3.4 \%)$ & $22(3.1 \%)$ & \\
\hline Geographic region & & & 1.00 & & & 1.00 \\
\hline United States, Canada & $312(15.9 \%)$ & $314(15.8 \%)$ & & $114(15.9 \%)$ & $113(15.7 \%)$ & \\
\hline Mexico, Central/South America & $502(25.6 \%)$ & $512(25.8 \%)$ & & $191(26.7 \%)$ & $188(26.2 \%)$ & \\
\hline Western Europe, Australia, New Zealand, Middle East & $234(11.9 \%)$ & $240(12.1 \%)$ & & $69(9.6 \%)$ & $73(10.2 \%)$ & \\
\hline Eastern Europe, Africa & $582(29.6 \%)$ & $580(29.2 \%)$ & & $171(23.9 \%)$ & 175 (24.4\%) & \\
\hline Asia/Pacific & 333 (17.0\%) & 337 (17.0\%) & & 171 (23.9\%) & 169 (23.5\%) & \\
\hline Smoking & 327 (16.7\%) & 300 (15.1\%) & 0.19 & $56(7.8 \%)$ & $51(7.1 \%)$ & 0.60 \\
\hline Hypertension & $1586(80.8 \%)$ & $1590(80.2 \%)$ & 0.63 & 654 (91.3\%) & 639 (89.0\%) & 0.14 \\
\hline Previous Ml & $1711(87.2 \%)$ & $1748(88.1 \%)$ & 0.35 & $634(88.5 \%)$ & 641 (89.3\%) & 0.66 \\
\hline $\mathrm{PCl}$ & $1253(63.8 \%)$ & $1248(62.9 \%)$ & 0.56 & 430 (60.1\%) & 441 (61.4\%) & 0.60 \\
\hline CABG & 221 (11.3\%) & 237 (12.0\%) & 0.50 & $120(16.8 \%)$ & $110(15.3 \%)$ & 0.46 \\
\hline HF history & $480(24.5 \%)$ & 495 (25.0\%) & 0.71 & 282 (39.4\%) & 276 (38.4\%) & 0.71 \\
\hline Previous stroke & 119 (6.1\%) & 115 (5.8\%) & 0.73 & 74 (10.3\%) & $80(11.1 \%)$ & 0.62 \\
\hline PAD & $143(7.3 \%)$ & $166(8.4 \%)$ & 0.20 & 109 (15.2\%) & $96(13.4 \%)$ & 0.31 \\
\hline AFib & 108 (5.5\%) & 101 (5.1\%) & 0.57 & 79 (11.0\%) & $88(12.3 \%)$ & 0.47 \\
\hline $\mathrm{eGFR} *\left(\mathrm{ml} / \mathrm{min} / 1.73 \mathrm{~m}^{2}\right)$, mean $\pm \mathrm{SD}$ & $79.7 \pm 16.9$ & $79.3 \pm 16.8$ & 0.43 & $47.2 \pm 13.7$ & $47.6 \pm 13.8$ & 0.57 \\
\hline $\mathrm{eGFR}^{*}<60 \mathrm{ml} / \mathrm{min} / 1.73 \mathrm{~m}^{2}$ & $194(9.9 \%)$ & $171(8.6 \%)$ & 0.17 & $599(83.7 \%)$ & $601(83.7 \%)$ & 0.98 \\
\hline $\mathrm{eGFR}<30 \mathrm{ml} / \mathrm{min} / 1.73 \mathrm{~m}^{2}$ & - & - & - & $77(10.8 \%)$ & $77(10.8 \%)$ & 0.99 \\
\hline Index ACS Event Type & & & 0.76 & & & 0.57 \\
\hline Myocardial Infarction & $1513(77.3 \%)$ & $1521(76.9 \%)$ & & $555(77.6 \%)$ & $563(78.9 \%)$ & \\
\hline Unstable Angina & $445(22.7 \%)$ & $458(23.1 \%)$ & & $160(22.4 \%)$ & $151(21.1 \%)$ & \\
\hline Time from index ACS to randomization, median (IQR) & $45.0(29.0,63.0)$ & $44.0(30.0,63.0)$ & 0.68 & $44.0(30.0,65.0)$ & $43.0(29.0,66.0)$ & 0.56 \\
\hline Troponin I (ng/L), median (IQR) & $7.8(4.3,16.5)$ & $7.7(3.8,17.0)$ & 0.44 & $12.8(6.4,27.7)$ & $14.0(7.1,30.2)$ & 0.08 \\
\hline Heart rate $(\mathrm{bpm})$, mean $\pm \mathrm{SD}$ & $71.4 \pm 10.8$ & $71.6 \pm 10.4$ & 0.56 & $70.7 \pm 11.1$ & $71.0 \pm 11.4$ & 0.55 \\
\hline $\mathrm{SBP}(\mathrm{mmHg})$, mean $\pm \mathrm{SD}$ & $128.5 \pm 16.7$ & $127.9 \pm 15.8$ & 0.21 & $131.1 \pm 17.6$ & $131.2 \pm 17.2$ & 0.93 \\
\hline $\mathrm{DBP}(\mathrm{mmHg})$, mean $\pm \mathrm{SD}$ & $76.9 \pm 9.5$ & $76.6 \pm 9.4$ & 0.41 & $75.5 \pm 10.1$ & $75.4 \pm 10.3$ & 0.95 \\
\hline Total cholesterol $(\mathrm{mg} / \mathrm{dL})$, mean $\pm \mathrm{SD}$ & $153.5 \pm 42.2$ & $151.7 \pm 43.1$ & 0.19 & $158.6 \pm 46.4$ & $159.8 \pm 46.6$ & 0.62 \\
\hline $\mathrm{LDL}$ cholesterol $(\mathrm{mg} / \mathrm{dL})$, mean $\pm \mathrm{SD}$ & $78.1 \pm 33.6$ & $76.6 \pm 33.2$ & 0.17 & $81.0 \pm 37.2$ & $83.4 \pm 38.6$ & 0.24 \\
\hline $\mathrm{HDL}$ cholesterol $(\mathrm{mg} / \mathrm{dL})$, mean $\pm \mathrm{SD}$ & $42.8 \pm 10.0$ & $43.2 \pm 10.7$ & 0.25 & $43.8 \pm 11.1$ & $43.1 \pm 11.2$ & 0.25 \\
\hline Triglycerides $(\mathrm{mg} / \mathrm{dL})$, mean $\pm \mathrm{SD}$ & $165.5 \pm 108.7$ & $160.9 \pm 105.5$ & 0.18 & $168.8 \pm 98.2$ & $167.7 \pm 90.8$ & 0.84 \\
\hline UACR (mg/g creat.), mean \pm SD & $17.6 \pm 54.1$ & $18.1 \pm 69.1$ & 0.83 & $67.7 \pm 152.1$ & $74.1 \pm 166.6$ & 0.53 \\
\hline
\end{tabular}


Table 1 Baseline characteristics of the study population by screening renal function strata and study drug (Continued)

\begin{tabular}{|c|c|c|c|c|c|c|}
\hline \multirow{2}{*}{$\begin{array}{l}\text { Renal function strata } \\
\text { Study drug }\end{array}$} & \multicolumn{3}{|c|}{ eGFR $\geq 60$ stratum } & \multicolumn{3}{|c|}{ eGFR $<60$ stratum } \\
\hline & Placebo & Alogliptin & $p$ value & Placebo & Alogliptin & $p$ value \\
\hline C-reactive protein $(\mathrm{mg} / \mathrm{dL})$, mean $\pm \mathrm{SD}$ & $5.1 \pm 12.1$ & $5.1 \pm 12.5$ & 0.94 & $7.0 \pm 14.9$ & $6.8 \pm 18.8$ & 0.79 \\
\hline Antiplatelet agents & 1911 (97.4\%) & $1933(97.5 \%)$ & 0.80 & $691(96.5 \%)$ & $697(97.1 \%)$ & 0.54 \\
\hline Beta-blockers & $1624(82.7 \%)$ & $1623(81.8 \%)$ & 0.47 & $579(80.9 \%)$ & $585(81.5 \%)$ & 0.77 \\
\hline ACEi/ARBs & $1641(83.6 \%)$ & $1626(82.0 \%)$ & 0.18 & $569(79.5 \%)$ & $575(80.1 \%)$ & 0.77 \\
\hline Statins & $1796(91.5 \%)$ & $1798(90.7 \%)$ & 0.37 & $624(87.2 \%)$ & $648(90.3 \%)$ & 0.064 \\
\hline Antidiabetic agents & $1948(99.2 \%)$ & $1968(99.2 \%)$ & 0.98 & $701(97.9 \%)$ & $708(98.6 \%)$ & 0.31 \\
\hline Insulin & $550(28.0 \%)$ & $526(26.5 \%)$ & 0.29 & $262(36.6 \%)$ & $267(37.2 \%)$ & 0.82 \\
\hline Metformin & $1437(73.2 \%)$ & $1424(71.8 \%)$ & 0.33 & $368(51.4 \%)$ & $333(46.4 \%)$ & 0.057 \\
\hline Thiazolidinediones & $42(2.1 \%)$ & $41(2.1 \%)$ & 0.87 & $22(3.1 \%)$ & $26(3.6 \%)$ & 0.56 \\
\hline Sulfonylureas & $927(47.2 \%)$ & $946(47.7 \%)$ & 0.76 & $310(43.3 \%)$ & $320(44.6 \%)$ & 0.63 \\
\hline Calcium channel blockers & $388(19.8 \%)$ & 375 (18.9\%) & 0.50 & $223(31.1 \%)$ & $211(29.4 \%)$ & 0.47 \\
\hline Diuretics (any) & $616(31.4 \%)$ & $624(31.5 \%)$ & 0.95 & $393(54.9 \%)$ & $381(53.1 \%)$ & 0.49 \\
\hline
\end{tabular}

Stratification according to renal function was performed at the baseline visit, as follows: (1) "normal renal function" stratum if eGFR $\geq 60 \mathrm{ml} / \mathrm{min} / 1.73 \mathrm{~m}^{2}$ or (2) "impaired renal function" stratum if eGFR $<60 \mathrm{ml} / \mathrm{min} / 1.73 \mathrm{~m}^{2}$

MI myocardial infarction, $P C I$ percutaneous coronary intervention, $C A B G$ coronary-artery bypass grafting, $H F$ heart failure, $P A D$ peripheral artery disease, $A F i b$ atrial fibrillation, eGFR estimated glomerular filtration rate, $A C S$ acute coronary syndrome, SBP systolic blood pressure, DBP diastolic blood pressure, ACEi/ARBs angiotensin converting enzyme inhibitors/angiotensin receptor blockers, UACR urinary albumin-to-creatinine ratio *eGFR at randomization, that occurred 9 (7-13) days after the baseline visit

between renal function strata $=0.021$ (Table $2(\mathrm{~A}))$. The components of the primary endpoint and the totality of the fatal events are presented in Table 2 (B). Within the eGFR $\geq 60$ stratum, non-fatal myocardial infarction occurred in $113(5.8 \%)$ patients in the placebo group and $99(5.0 \%)$ patients in the alogliptin group, HR $(95 \% \mathrm{CI})=$ $0.86(0.66-1.13)$, whereas within eGFR $<60$ stratum, non-fatal myocardial infarction occurred in 60 (8.4\%) patients in the placebo group and $88(12.3 \%)$ patients in the alogliptin group, HR $(95 \% \mathrm{CI})=1.48(1.07-2.06) ; p$ for interaction $=0.013$. Within the eGFR $\geq 60$ stratum, cardiovascular death occurred in $72(3.7 \%)$ patients in the placebo group and $44(2.2 \%)$ patients in the alogliptin group, HR $(95 \% \mathrm{CI})=0.61(0.42-0.88)$, whereas
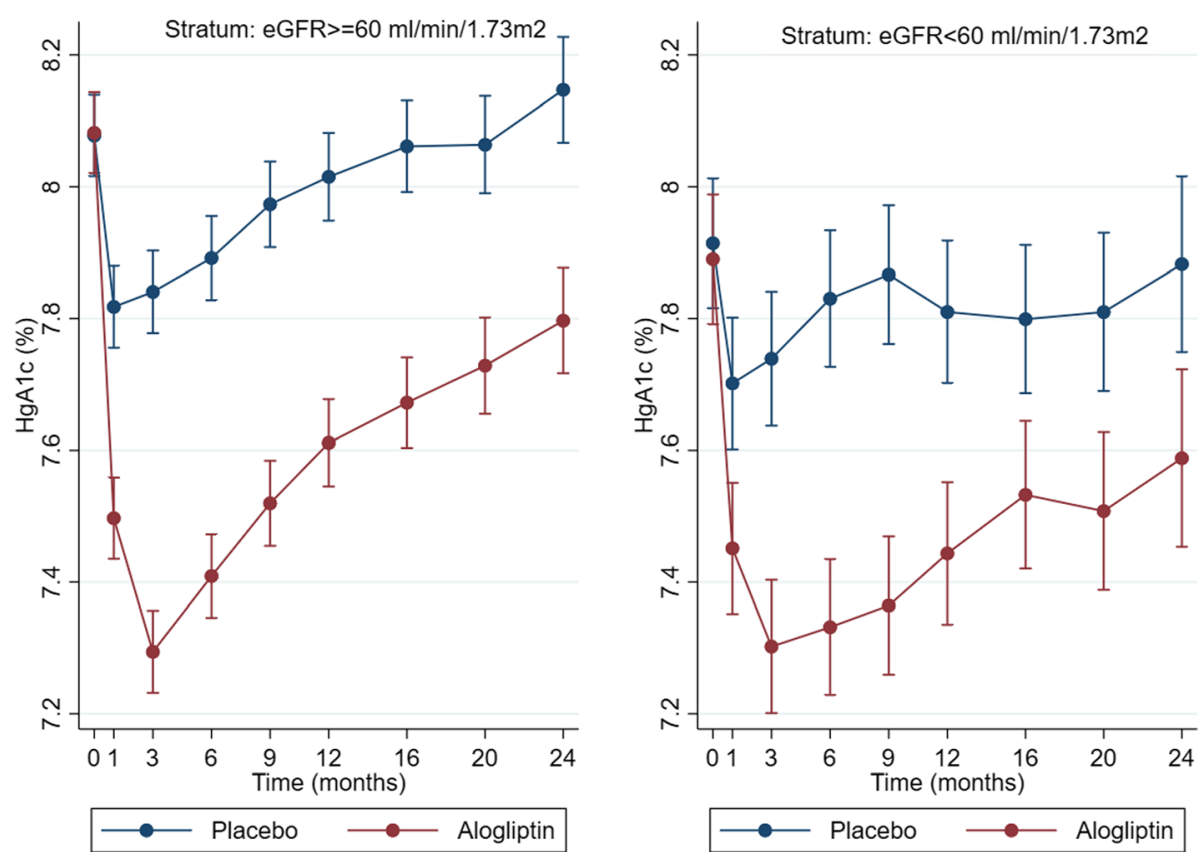

Fig. 1 Glycated hemoglobin levels over time by study treatment and renal function strata. $p$ value $<0.001$ for all time point comparisons within each eGFR stratum. Global $p$ value for between eGFR strata interaction = 0.61. HgA1c, glycated hemoglobin; eGFR, estimated glomerular filtration rate 

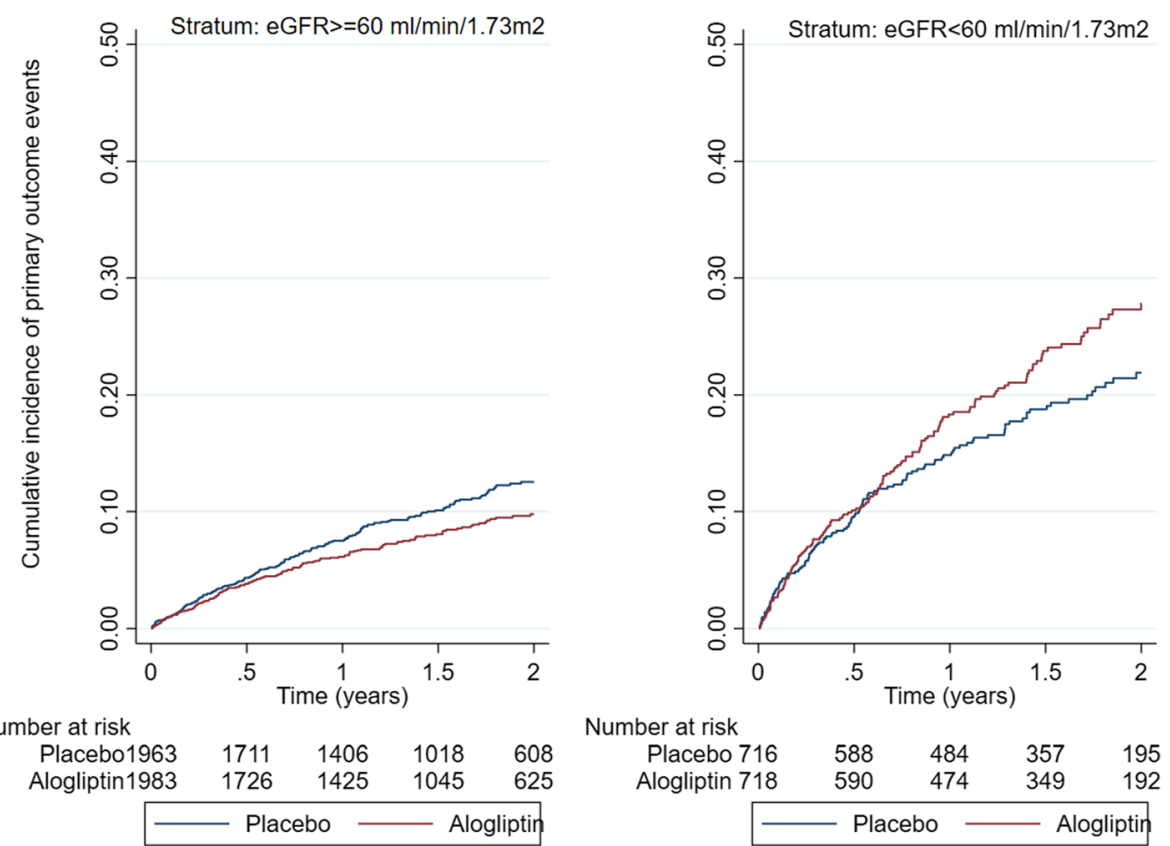

Fig. 2 Cumulative incidence Kaplan-Meier curves by study treatment and renal function strata. $p$ value for between eGFR strata interaction = 0.014. eGFR, estimated glomerular filtration rate

Table 2 Study endpoints by renal function strata

(A) Primary and secondary endpoints by renal function strata

$\begin{array}{llllll}\text { Endpoint } & \text { Renal function } & \text { Placebo } & \text { Alogliptin } & \text { HR (95\% Cl) } & \text { Interaction } \boldsymbol{p} \text { value } \\ \text { Primary } & \mathrm{eGFR} \geq 60 & 192(9.8 \%) & 157(7.9 \%) & 0.81(0.65-0.99) & 0.014 \\ & \mathrm{eGFR}<60 & 124(17.3 \%) & 148(20.6 \%) & 1.20(0.95-1.53) & \\ \text { Secondary } & \mathrm{eGFR} \geq 60 & 226(11.5 \%) & 189(9.5 \%) & 0.82(0.68-0.99) & 0.021 \\ & \mathrm{eGFR}<60 & 133(18.6 \%) & 155(21.6 \%) & 1.17(0.93-1.47) & \end{array}$

(B) Components of primary endpoint and other endpoints by renal function strata

\begin{tabular}{|c|c|c|c|c|c|}
\hline Components of primary endpoint & Renal function & Placebo & Alogliptin & $\mathrm{HR}(95 \% \mathrm{Cl})$ & Interaction $p$ value \\
\hline \multirow[t]{2}{*}{ CV death } & $\mathrm{eGFR} \geq 60$ & $60(3.1 \%)$ & $37(1.9 \%)$ & $0.61(0.41-0.92)$ & \multirow[t]{2}{*}{0.079} \\
\hline & eGFR $<60$ & $51(7.1 \%)$ & $52(7.2 \%)$ & $1.01(0.69-1.48)$ & \\
\hline \multirow[t]{2}{*}{ Non-fatal Ml* } & $\mathrm{eGFR} \geq 60$ & $113(5.8 \%)$ & $99(5 \%)$ & $0.86(0.66-1.13)$ & \multirow[t]{2}{*}{0.013} \\
\hline & $\mathrm{eGFR}<60$ & $60(8.4 \%)$ & $88(12.3 \%)$ & $1.48(1.07-2.06)$ & \\
\hline \multirow[t]{2}{*}{ Non-fatal stroke } & $\mathrm{eGFR} \geq 60$ & $19(1 \%)$ & $21(1.1 \%)$ & $1.20(0.95-1.53)$ & \multirow[t]{2}{*}{0.28} \\
\hline & $\mathrm{eGFR}<60$ & $13(1.8 \%)$ & $8(1.1 \%)$ & $0.61(0.25-1.47)$ & \\
\hline Other endpoints & Renal function & Placebo & Alogliptin & $\mathrm{HR}(95 \% \mathrm{Cl})$ & Interaction $p$ value \\
\hline \multirow[t]{2}{*}{ All-cause death } & $\mathrm{eGFR} \geq 60$ & $89(4.5 \%)$ & $74(3.7 \%)$ & $0.82(0.60-1.12)$ & \multirow[t]{2}{*}{0.56} \\
\hline & $\mathrm{eGFR}<60$ & $84(11.7 \%)$ & $79(11.0 \%)$ & $0.93(0.68-1.27)$ & \\
\hline \multirow[t]{2}{*}{ All CV deaths } & $\mathrm{eGFR} \geq 60$ & $72(3.7 \%)$ & $44(2.2 \%)$ & $0.61(0.42-0.88)$ & \multirow[t]{2}{*}{0.013} \\
\hline & eGFR $<60$ & $58(8.1 \%)$ & $68(9.5 \%)$ & $1.16(0.82-1.65)$ & \\
\hline \multirow[t]{2}{*}{ HF hospitalizations } & eGFR $\geq 60$ & $43(2.2 \%)$ & $44(2.2 \%)$ & $1.01(0.67-1.55)$ & \multirow[t]{2}{*}{0.32} \\
\hline & $\mathrm{eGFR}<60$ & $46(6.4 \%)$ & $62(8.6 \%)$ & $1.35(0.92-1.97)$ & \\
\hline
\end{tabular}

The primary endpoint was a composite of cardiovascular death, non-fatal Ml, and non-fatal stroke. The secondary endpoint was a composite of death from cardiovascular causes, nonfatal myocardial infarction, nonfatal stroke, or urgent revascularization due to unstable angina within $24 \mathrm{~h}$ after hospital admission MI myocardial infarction, $C V$ cardiovascular, $H F$ heart failure, eGFR estimated glomerular filtration rate in $\mathrm{ml} / \mathrm{min} / 1.73 \mathrm{~m} 2$

${ }^{*}$ After adjustment for the competing risk of death, $\mathrm{HR}(95 \% \mathrm{Cl})$ is $0.87(0.66-1.14)$ for normal and $1.50(1.08-2.08)$ for impaired renal function 
within the eGFR $<60$ stratum, cardiovascular death occurred in $58(8.1 \%)$ patients in the placebo group and 68 (9.5\%) patients in the alogliptin group, HR $(95 \% \mathrm{CI})=$ $1.16(0.82-1.65) ; p$ for interaction between renal function strata $=0.013$. No treatment-by-eGFR strata interactions were present for all-cause death, heart failure hospitalizations, and non-fatal stroke (Table 2 (B)). These results were confirmed using models that account for competing events. The respective event rates (per 100 person-years) and absolute rate differences are depicted in Additional file: Table S3.

\section{Primary and secondary endpoints by eGFR subgroups}

The eGFR used for the prespecified stratification was performed at the screening visit that occurred 9 days (pct ${ }_{25-75} 7-13$ ) before the randomization visit; $16 \%$ of patients stratified in the eGFR $<60$ stratum improved their eGFR to $\geq 60$ from the screening to the randomization visit, whereas $9 \%$ decreased their eGFR from $\geq 60$ to $<60 \mathrm{ml} / \mathrm{min} / 1.73 \mathrm{~m}^{2}$ (Additional file: Table S4). In the main EXAMINE trial report [7], the eGFR used for the "subgroup-interaction" assessment was the eGFR from the randomization visit (and not the prespecified renal function stratification). Nevertheless, in the main report (supplemental material), a significant treatment by eGFR subgroup interaction was present: eGFR $\geq 60 \mathrm{HR}=0.84(0-68-104)$ vs. eGFR $<60 \mathrm{HR}=1.15$ $(0.91-1.46) ; p$ for interaction $=0.046$.

\section{Adverse events by renal function strata}

Patients in the alogliptin group had more hypoglycemic events (but with low absolute proportions) in the eGFR $\geq 60$ stratum $6.1 \%$ vs. $4.6 \%$, but not in the eGFR $<60$ stratum: $8.5 \%$ vs. $11.5 \%$; $p$ for interaction $=0.007$. Serious hypoglycemia was more frequently observed in patients with eGFR $<60$, but the absolute rates were low $(<2 \%)$ and not different between the alogliptin and placebo groups; $p$ for interaction $=0.14$. Elevation of serum aminotransferases ( $>3 \times$ the upper limit of normal) and other adverse events by treatment allocation did not differ between the renal function strata (Table 3).

\section{Discussion}

In this post hoc analysis of the EXAMINE trial, we evaluated the impact of randomization to alogliptin versus placebo within prespecified strata of renal function at the screening visit: eGFR $\geq 60$ and eGFR $<60 \mathrm{ml} / \mathrm{min} / 1.73 \mathrm{~m}^{2}$. We found that randomization to alogliptin was associated with a reduction in the primary 3-point MACE outcome in participants within the eGFR $\geq 60$ stratum but not among participants within the eGFR $<60$ stratum who might have experienced an excess of adverse events, particularly MI.
Stratified randomization is recommended when there is a strong a priori expectation that the stratification variable is prognostic for treatment response. Treatment balance is thereby maintained within each stratum resulting in a more efficient comparison of treatment effect [15]. The inclusion of renal function as a stratification variable thus ensured a better balance between the treatment and placebo arms for both the eGFR $\geq 60$ and eGFR $<60$ strata. Moreover, because the stratification by renal function was identified at screening, before any data were observed, it lends greater weight to the results than the subsequent subgroup analysis.

Renal function is a major outcome driver and portends a high risk of future cardiovascular events in patients with and without diabetes $[9,10]$. In the subgroup analyses reported within the primary results of the EXAMINE trial, the impact of alogliptin versus placebo on the primary outcome was presented based on the randomization (and not the screening) renal function [7]. Notwithstanding, a statistically significant treatment interaction by randomization eGFR subgroup was also observed [7]. The results between the two analyses (i.e., screening and randomization) are therefore directionally consistent.

Alogliptin could reduce the risk of cardiovascular death among patients within the eGFR $\geq 60$ stratum but not in patients within the eGFR $<60$ stratum, where an excess of adverse events, particularly MI, could be observed. Alogliptin is primarily eliminated by the kidney, with approximately $60-80 \%$ of the dose excreted unchanged in the urine [11]. In patients with renal impairment, alogliptin can have up to 3-fold higher accumulation [16]. The long-term, large-scale effects of alogliptin in patients with renal impairment remain largely unknown [16-18]. An analysis of the FDA Adverse Event Reporting System (FAERS) from 2006 to 2015 studying 13.4 million adverse event reports for diabetics and cardiovascular drugs found an excess for signals of disproportionate reporting of MI with alogliptin (compared with other "gliptins") [15]. These large-scale registry data align with our randomized placebo-controlled data showing a $48 \%$ excess risk of myocardial infarction (on a relative scale) and +2.8 events per 100 person-years (on an absolute scale) in patients allocated to alogliptin within the eGFR $<60$ stratum. Data on the subgroup of patients with renal dysfunction are not shown in this FAERS report [15]; therefore, one cannot ascertain if the excess risk was driven by patients with renal impairment. To date, no other cardiovascular safety trial of a DPP-4 inhibitor versus placebo (or active comparator) has demonstrated an excess of risk of MACE with the DPP-4 inhibitor based on renal function [19-22]. 
Table 3 Safety endpoints

\begin{tabular}{|c|c|c|c|c|}
\hline Adverse events & Placebo & Alogliptin & $p$ value & Inter. $p$ \\
\hline \multicolumn{5}{|l|}{ eGFR $\geq 60$ stratum } \\
\hline Any serious adverse event & $607(30.9 \%)$ & $564(28.4 \%)$ & 0.088 & 0.42 \\
\hline Serious hypoglycemia & $4(0.2 \%)$ & $9(0.5 \%)$ & 0.17 & 0.14 \\
\hline Any adverse event & $1490(75.9 \%)$ & $1532(77.3 \%)$ & 0.32 & 0.95 \\
\hline Any hypoglycemia & $91(4.6 \%)$ & $120(6.1 \%)$ & 0.048 & 0.007 \\
\hline Pancreatitis & & & & 0.36 \\
\hline Acute & $5(0.3 \%)$ & $5(0.3 \%)$ & 0.99 & \\
\hline Chronic & $4(0.2 \%)$ & $2(0.1 \%)$ & 0.41 & \\
\hline Angioedema & $6(0.3 \%)$ & $7(0.4 \%)$ & 0.80 & 0.78 \\
\hline Malignancy & $30(1.5 \%)$ & $38(1.9 \%)$ & 0.35 & 0.28 \\
\hline Dialysis & $3(0.2 \%)$ & $1(0.1 \%)$ & 0.31 & 0.27 \\
\hline $\begin{array}{l}\text { Serum aminotransferases }>3 \times \text { upper limit } \\
\text { of normal at any time during trial }\end{array}$ & & & & 0.11 \\
\hline Alanine aminotransferase & 37 (1.9\%) & $43(2.2 \%)$ & 0.53 & \\
\hline Aspartate aminotransferase & $32(1.6 \%)$ & $27(1.4 \%)$ & 0.49 & \\
\hline \multicolumn{5}{|l|}{ eGFR $<60$ stratum } \\
\hline Any serious adverse event & $345(48.2 \%)$ & $343(47.8 \%)$ & 0.88 & 0.42 \\
\hline Serious hypoglycemia & $12(1.7 \%)$ & $9(1.3 \%)$ & 0.51 & 0.14 \\
\hline Any adverse event & $621(86.7 \%)$ & $628(87.5 \%)$ & 0.68 & 0.95 \\
\hline Any hypoglycemia & $82(11.5 \%)$ & $61(8.5 \%)$ & 0.062 & 0.007 \\
\hline Pancreatitis & & & & 0.36 \\
\hline Acute & $3(0.4 \%)$ & $7(1.0 \%)$ & 0.21 & \\
\hline Chronic & 0 & $3(0.4 \%)$ & 0.083 & \\
\hline Angioedema & $7(1.0 \%)$ & $10(1.4 \%)$ & 0.45 & 0.78 \\
\hline Malignancy & $21(2.9 \%)$ & $17(2.4 \%)$ & 0.51 & 0.28 \\
\hline Dialysis & $19(2.7 \%)$ & $23(3.2 \%)$ & 0.54 & 0.27 \\
\hline Serum aminotransferases $>3 \times$ upper limit of normal at any time during trial & & & & 0.11 \\
\hline Alanine aminotransferase & $9(1.3 \%)$ & $21(2.9 \%)$ & 0.027 & \\
\hline Aspartate aminotransferase & $11(1.5 \%)$ & $21(2.9 \%)$ & 0.075 & \\
\hline
\end{tabular}

$p$ values were calculated by Fisher's exact test with no adjustment for multiple comparisons. Hypoglycemia was reported by site investigators. The upper limit of normal for the alanine aminotransferase was $25 \mathrm{U} / \mathrm{L}$ and for aspartate aminotransferase was $22 \mathrm{U} / \mathrm{L}$

eGFR estimated glomerular filtration rate in $\mathrm{ml} / \mathrm{min} / 1.73 \mathrm{~m}^{2}$, Inter. $p$ p value for interaction between eGFR strata and treatment allocation for each outcome in a logistic regression model

The analyses of the reported adverse events and repeated measures of cholesterol, blood pressure, and renal function in the EXAMINE trial do not provide additional insight on the potential mechanisms underlying the increased rate of myocardial infarction with alogliptin within the eGFR $<60$ stratum. Patients with eGFR $<60$ had higher proportion of hepatic cytolysis with alogliptin $(+1.6 \%$ serum alanine aminotransferase $>3 \times$ the upper limit of normal), but the absolute number of events was low $(<3 \%)$ and does not, per se, explain the observed risk. Serious hypoglycemia was also more frequently observed in patients with eGFR $<60$, but the absolute rates were also low $(<2 \%)$ and not different between alogliptin and placebo. In concordance with other "gliptin" reports, alogliptin did not have major effect in albuminuria and renal function regardless of the renal function stratum. Natriuretic peptides were also not affected by alogliptin treatment $[8,23]$.

\section{Limitations}

In the advent of a qualitative stratum by treatment interaction (as observed herein), then the estimate of the common hazard ratio obtained from the stratified Cox model cannot be interpreted and the better option is to report the hazard ratio estimates and hypothesis test results separately for the two strata (as here performed). It is of worth noting that in 
this context, the interaction tests for treatment by renal function were statistically significant for both the primary and secondary endpoints even though it is well known that such tests have low power [15]. Nevertheless, it is not possible to control the family-wise error rate of a joint hypothesis that involves both the treatment effect and the strata by treatment interaction since it was not prespecified in the EXAMINE trial statistical analysis plan as part of the hierarchical testing strategy, therefore these findings cannot be corrected for multiplicity of testing. Furthermore, the EXAMINE trial is underpowered to assess the treatment effect in each stratum separately and even less powered to assess the effects in patients with severely impaired renal function. For these reasons, the findings presented here should be regarded as "hypothesis generating" and further investigation is required, particularly to assess the safety of alogliptin in patients with renal dysfunction.

\section{Conclusion}

Alogliptin may benefit patients with normal/near normal renal function, but may be detrimental to patients with impaired renal function. These hypothesis-generating findings require further validation to assess the potential benefit and risk of alogliptin across the renal function spectrum among patients with type 2 diabetes who had had a recent acute coronary syndrome.

\section{Supplementary information}

Supplementary information accompanies this paper at https://doi.org/10. 1186/s12916-020-01616-8.

Additional file 1: Table S1. Baseline characteristics of the study population by screening renal function strata. Table S2. Baseline and changes from baseline to the last visit for lipoproteins, UACR and estimated glomerular filtration rate. Table S3. Major study end-points: event rates (per 100py) and event rate comparison. Table S4. eGFR changes between the baseline and randomization visit. Figure S1. Changes from baseline by treatment arm (within each eGFR stratum) for total, LDL and HDL cholesterol, body mass index, creatinine, eGFR, UACR, systolic and diastolic blood pressure, and c-reactive protein.

\section{Acknowledgements}

JPF, PR, and FZ are supported by a public grant overseen by the French National Research Agency (ANR) as part of the second "Investissements d'Avenir" programme (ANR-15-RHU-0004).

\section{Authors' contributions}

J.P.F. performed the statistical analysis and drafted the manuscript; C.M. supervised the statistical analysis and edited the manuscript; A.S. drafted the manuscript; S.E.N. provided critical input and edited the manuscript; P.R. provided critical input and edited the manuscript; F.Z. supervised the work, provided critical input, and edited the manuscript. The authors read and approved the final manuscript.

\section{Funding}

None.

Availability of data and materials

The data and materials may be available upon reasonable request.

\section{Ethics approval and consent to participate}

The appropriate national and institutional regulatory authorities and ethics committees approved the study design, and all participants provided written informed consent according to the World Medical Association Declaration of Helsinki.

\section{Consent for publication}

Not applicable.

\section{Competing interests}

The authors declare that they have no competing interests.

\section{Author details}

'Université de Lorraine, Centre d'Investigations Cliniques Plurithématique Inserm 1433, Nancy, France, CHRU de Nancy, Inserm U1116, Nancy, France, FCRIN INI-CRCT, Nancy, France. ${ }^{2}$ INSERM U1116, CHRU, F-CRIN INI-CRCT (Cardiovascular and Renal Clinical Trialists), 4 rue du Morvan, 54500 Vandoeuvre les Nancy, Nancy, France. ${ }^{3}$ Cytel Corportation, Cambridge, MA, USA. ${ }^{4}$ Harvard T.H. Chan School of Public Health, Boston, MA, USA. ${ }^{5}$ Division of Cardiology, McGill University Health Centre, McGill University, Montreal, Quebec, Canada. ${ }^{6}$ Cleveland Clinic Coordinating Center for Clinical Research, Department of Cardiovascular Medicine, Cleveland Clinic, Cleveland, $\mathrm{OH}$, USA.

Received: 10 March 2020 Accepted: 4 May 2020

Published online: 04 June 2020

\section{References}

1. Meigs JB. Epidemiology of cardiovascular complications in type 2 diabetes mellitus. Acta Diabetol. 2003:40(Suppl 2):S358-61.

2. Prattichizzo F, La Sala L, Ryden L, Marx N, Ferrini M, Valensi P, Ceriello A. Glucose-lowering therapies in patients with type 2 diabetes and cardiovascular diseases. Eur J Prev Cardiol. 2019:26(2 suppl):73-80.

3. Goldfine AB. Assessing the cardiovascular safety of diabetes therapies. N Engl J Med. 2008:359(11):1092-5.

4. Nissen SE, Wolski K. Effect of rosiglitazone on the risk of myocardial infarction and death from cardiovascular causes. N Engl J Med. 2007;356(24): 2457-71

5. Hennekens $\mathrm{CH}$, Hebert PR, Schneider WR, O'Brien P, Demets D, Borer JS. Academic perspectives on the United States Food and Drug Administration's guidance for industry on diabetes mellitus. Contemp Clin Trials. 2010;31(5):411-3.

6. Holst JJ, Deacon CF. Inhibition of the activity of dipeptidyl-peptidase IV as a treatment for type 2 diabetes. Diabetes. 1998:47(11):1663-70.

7. White WB, Cannon CP, Heller SR, Nissen SE, Bergenstal RM, Bakris GL, Perez AT, Fleck PR, Mehta CR, Kupfer S, Wilson C, Cushman WC, Zannad F. Alogliptin after acute coronary syndrome in patients with type 2 diabetes. N Engl J Med. 2013:369(14):1327-35.

8. Zannad F, Cannon CP, Cushman WC, Bakris GL, Menon V, Perez AT, Fleck PR, Mehta CR, Kupfer S, Wilson C, Lam H, White WB. Heart failure and mortality outcomes in patients with type 2 diabetes taking alogliptin versus placebo in EXAMINE: a multicentre, randomised, double-blind trial. Lancet. 2015; 385(9982):2067-76.

9. Fox CS, Matsushita K, Woodward M, Bilo HJ, Chalmers J, Heerspink HJ, Lee BJ, Perkins RM, Rossing P, Sairenchi T, Tonelli M, Vassalotti JA, Yamagishi K, Coresh J, de Jong PE, Wen CP, Nelson RG. Associations of kidney disease measures with mortality and end-stage renal disease in individuals with and without diabetes: a meta-analysis. Lancet. 2012;380(9854):1662-73.

10. Tonelli M, Muntner P, Lloyd A, Manns BJ, Klarenbach S, Pannu N, James MT, Hemmelgarn BR. Risk of coronary events in people with chronic kidney disease compared with those with diabetes: a population-level cohort study. Lancet. 2012;380(9844):807-14.

11. Covington P, Christopher R, Davenport M, Fleck P, Mekki QA, Wann ER, Karim A. Pharmacokinetic, pharmacodynamic, and tolerability profiles of the dipeptidyl peptidase-4 inhibitor alogliptin: a randomized, double-blind, placebo-controlled, multiple-dose study in adult patients with type 2 diabetes. Clin Ther. 2008;30(3):499-512.

12. White WB, Bakris GL, Bergenstal RM, Cannon CP, Cushman WC, Fleck P, Heller S, Mehta C, Nissen SE, Perez A, Wilson C, Zannad F. EXamination of cArdiovascular outcoMes with alogliptIN versus standard of carE in patients with type 2 diabetes mellitus and acute coronary syndrome (EXAMINE): a 
cardiovascular safety study of the dipeptidyl peptidase 4 inhibitor alogliptin in patients with type 2 diabetes with acute coronary syndrome. Am Heart J. 2011;162(4):620-626.e1.

13. Levey AS, Stevens LA, Schmid CH, Zhang YL, Castro AF 3rd, Feldman HI, Kusek JW, Eggers P, Van Lente F, Greene T, Coresh J. A new equation to estimate glomerular filtration rate. Ann Intern Med. 2009;150:604-12.

14. JP, F.; RJ, G., A proportional hazards model for the subdistribution of a competing risk. J Am Stat Assoc. 1999, 94 :496-509.

15. Baksh SN, McAdams-DeMarco M, Segal JB, Alexander GC. Cardiovascular safety signals with dipeptidyl peptidase-4 inhibitors: a disproportionality analysis among high-risk patients. Pharmacoepidemiol Drug Saf. 2018;27(6): 660-7.

16. Christopher R, Karim A. Clinical pharmacology of alogliptin, a dipeptidyl peptidase-4 inhibitor, for the treatment of type 2 diabetes. Expert Rev Clin Pharmacol. 2009:2(6):589-600.

17. Sakai Y, Suzuki A, Mugishima K, Sumi Y, Otsuka Y, Otsuka T, Ohno D, Murasawa T, Tsuruoka S. Effects of alogliptin in chronic kidney disease patients with type 2 diabetes. Intern Med. 2014;53(3):195-203.

18. Scheen AJ. Pharmacokinetics and clinical use of incretin-based therapies in patients with chronic kidney disease and type 2 diabetes. Clin Pharmacokinet. 2015;54(1):1-21.

19. Green JB, Bethel MA, Armstrong PW, Buse JB, Engel SS, Garg J, Josse R, Kaufman KD, Koglin J, Korn S, Lachin JM, McGuire DK, Pencina MJ, Standl E, Stein PP, Suryawanshi S, Van de Werf F, Peterson ED, Holman RR. Effect of sitagliptin on cardiovascular outcomes in type 2 diabetes. N Engl J Med. 2015;373(3):232-42.

20. Scirica BM, Bhatt DL, Braunwald E, Steg PG, Davidson J, Hirshberg B, Ohman P, Frederich R, Wiviott SD, Hoffman EB, Cavender MA, Udell JA, Desai NR, Mosenzon O, McGuire DK, Ray KK, Leiter LA, Raz I. Saxagliptin and cardiovascular outcomes in patients with type 2 diabetes mellitus. N Engl J Med. 2013;369(14):1317-26.

21. Rosenstock J, Kahn SE, Johansen OE, Zinman B, Espeland MA, Woerle HJ, Pfarr E, Keller A, Mattheus M, Baanstra D, Meinicke T, George JT, von Eynatten M, McGuire DK, Marx N. Effect of linagliptin vs glimepiride on major adverse cardiovascular outcomes in patients with type 2 diabetes: the CAROLINA randomized clinical trial. JAMA. 2019. https://doi.org/10.1001/ jama.2019.13772.

22. Rosenstock J, Perkovic V, Johansen OE, Cooper ME, Kahn SE, Marx N, Alexander JH, Pencina M, Toto RD, Wanner C, Zinman B, Woerle HJ, Baanstra D, Pfarr E, Schnaidt S, Meinicke T, George JT, von Eynatten M McGuire DK. Effect of linagliptin vs placebo on major cardiovascular events in adults with type 2 diabetes and high cardiovascular and renal risk: the CARMELINA randomized clinical trial. JAMA. 2019;321(1):69-79.

23. Walker SR, Komenda P, Khojah S, Al-Tuwaiji W, MacDonald K, Hiebert B, Tangri N, Nadurak SWD, Ferguson TW, Rigatto C. Dipeptidyl peptidase-4 inhibitors in chronic kidney disease: a systematic review of randomized clinical trials. Nephron. 2017;136(2):85-94.

\section{Publisher's Note}

Springer Nature remains neutral with regard to jurisdictional claims in published maps and institutional affiliations.

Ready to submit your research? Choose BMC and benefit from:

- fast, convenient online submission

- thorough peer review by experienced researchers in your field

- rapid publication on acceptance

- support for research data, including large and complex data types

- gold Open Access which fosters wider collaboration and increased citations

- maximum visibility for your research: over $100 \mathrm{M}$ website views per year

At $\mathrm{BMC}$, research is always in progress.

Learn more biomedcentral.com/submissions 